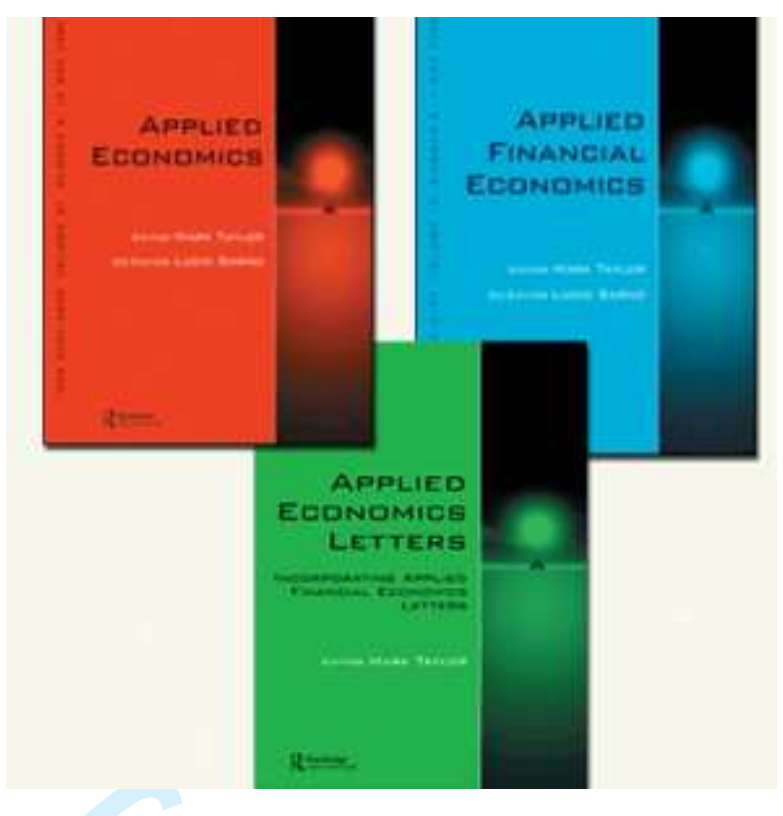

\title{
Economies of scale and scope in the provision of diagnostic techniques and therapeutic services in Portuguese hospitals
}

\begin{tabular}{|r|l|}
\hline Journal: & Applied Economics \\
\hline Manuscript ID: & APE-2009-0654.R1 \\
\hline Journal Selection: & Applied Economics \\
\hline Autho Submitted by the & 23-Feb-2011 \\
\hline Complete List of Authors: & $\begin{array}{l}\text { Gonçalves, Ricardo; Universidade Católica Portuguesa, Faculdade } \\
\text { de Economia e Gestão } \\
\text { Barros, Pedro; Universidade Nova de Lisboa, Nova School of } \\
\text { Business and Economics }\end{array}$ \\
\hline JEL Code: & $\begin{array}{l}\text { D24 - Production|Capital and Total Factor Productivity|Capacity < } \\
\text { D2 - Production and Organizations < D - Microeconomics, I12 - } \\
\text { Health Production: Nutrition, Mortality, Morbidity, Disability, etc. } \\
\text { I1 - Health < I - Health, Education, and Welfare, I18 - Government } \\
\text { Policy|Regulation|Public Health < I1 - Health < I - Health, } \\
\text { Education, and Welfare }\end{array}$ \\
\hline Keywords: & $\begin{array}{l}\text { translog cost function, economies of scale , economies of scope, } \\
\text { clinical services, hospitals }\end{array}$ \\
\hline
\end{tabular}




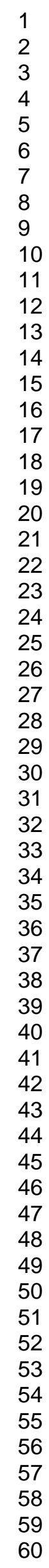

\section{SCHOLARONE ${ }^{m}$ \\ Manuscripts}

7

25

26

27
28

29

30

31

33

34

35

36

37

38

40

41

42

44

45

46

47

48

49

51

52

54

55

57

58

59

60 


\title{
Economies of scale and scope in the provision of diagnostic techniques and therapeutic services in Portuguese hospitals*
}

\author{
Ricardo Gonçalves ${ }^{\dagger}$ \\ Faculdade de Economia e Gestão, Universidade Católica Portuguesa (Porto) \\ Pedro Pita Barros \\ Nova School of Business \& Economics and CEPR (London)
}

February 2011

\begin{abstract}
This paper analyses the provision of auxiliary clinical services that are typically carried out within the hospital. We estimate a flexible cost function for three of the most important (costwise) diagnostic techniques and therapeutic services in Portuguese hospitals: Clinical Pathology, Medical Imaging and Physical Medicine and Rehabilitation. Our objective in carrying out this estimation is the evaluation of economies of scale and scope in the provision of these services. For all services, we find evidence of economies of scale and some evidence of economies of scope. We also find evidence of diminishing returns to management, whereby larger hospitals appear to have surpassed their optimal size. These results have important policy implications and can be related to the ongoing discussion of where and how should hospitals provide these services.
\end{abstract}

JEL Classification: D24, I12, I18

Keywords: translog cost function, economies of scale, economies of scope, clinical services, hospitals

\footnotetext{
${ }^{*}$ We would like to thank participants of the 11th Portuguese National Health Economics Conference (Porto, October 2009) and an anonymous referee for their useful comments and suggestions. Financial support from FCT (Foundation for Science and Technology) and POCI 2010 is gratefully acknowledged.

${ }^{\dagger}$ Corresponding author. Postal address: Faculdade de Economia e Gestão, Universidade Católica Portuguesa (Porto), Rua Diogo Botelho, 1327, 4169-005 Porto, Portugal. E-mail: rgoncalves@porto.ucp.pt.
} 


\section{Introduction}

Hospital efficiency and cost structure have received widespread attention in the literature. ${ }^{1}$ The analysis of hospitals' cost structure had an initial objective of (i) assessing economies of scale and (ii) understanding the increasing trend in hospital costs (Cowing and Holtmann, 1983). Grannemann et al. (1986) have added one further reason for the importance of hospitals' cost structure: changes in hospitals' reimbursement policies, particularly the introduction of prospective payments. Knowledge of the cost structure is necessary in order to understand the incentives underlying hospitals' output decisions under various reimbursement policies and, for policymakers, this information is crucial in order to define price levels and other details of the payment mechanism (such as whether services should be paid for in bundles or on a service by service basis, or whether different types of hospital should receive different prices). In addition to this, from a competition policy perspective, especially when assessing mergers between hospitals, a good understanding of the hospitals' cost structure is necessary in order to evaluate potential merger-related cost efficiencies (Vita, 1990; Preyra and Pink, 2006).

And yet little is known about cost structures of services within the hospital. In particular, some clinical (e.g. clinical pathology, medical imaging, pharmacy) and non-clinical services (e.g. car parking, computing, laundry, engineering, catering) are often considered inputs of production (Cowing and Holtmann, 1983; Vita, 1990), but no attention is paid to their own production process. Given that such activities usually have a significant weight in total costs, it is surprising that more research on the topic has not been carried out.

Moreover, there is often pressure or need to outsource the provision of such activities, or at the very least to benchmark their provision against private sector practices (Young, 2005). This is particularly important in the light of Coase's (1937) contribution to a proper understanding of the firm: in the provision of a particular service by a firm, it is important to compare the possibility of in-house production with the use of the market as a resource allocation mechanism (outsourcing) - often defined as a make-or-buy decision. A body of literature has emerged looking in detail at this dilemma, focusing on the role of transaction costs, asset specificity and incomplete contracts as crucial elements to guide a firm's make-or-buy decision (Williamson, 1975, 1979 and 1985; Grossman and Hart, 1986). More recently, Grossman and Helpman (2002) have explicitly modelled these trade-offs in a framework designed to analyse market structures, where integration and outsourcing emerge as "equilibrium phenomena".

This paper is a contribution to a more detailed analysis of the trade-offs involved in the make-orbuy decisions of some clinical services by hospitals. In particular, our objective is to shed light on an

\footnotetext{
${ }^{1}$ On efficiency, see, among others, Zuckerman et al. (1994), Rosko and Chilingerian (1999), Rosko (2001), Staat (2006) or Herr (2008). On cost structures, see, for example, Cowing and Holtmann (1983), Grannemann et al. (1986), Vitaliano (1987), Vita (1990), Fournier and Mitchell (1992), Aletras (1999), Li and Rosenman (2001) or Preyra and Pink (2006).
} 
important reason for outsourcing: the existence of economies of scale. As Williamson (1979) notes, by choosing to buy rather than make, and assuming transaction costs are negligible, an external supplier may be in a better position to take advantage of scale economies through aggregation of various firms' demands. Or, viewed from a different perspective, if transaction costs are significant or if outsourcing to private sector contractors is a politically delicate decision, in-house production may bring about benefits to hospitals which enjoy economies of scale and it may be sensible, whenever possible, for such hospitals to aggregate the production which would normally be carried out by other hospitals. Moreover, economies of scope may exist in the joint provision of several services. For those cases, joint service production would lead to lower costs, whilst for services which do not benefit from economies of scope, there is an economically sound argument for them to be produced independently from others, possibly even outsourced.

Hence, our objective is the evaluation of economies of scale and scope in the provision of auxiliary clinical services that are typically carried out within the hospital. In order to do this, we estimate a flexible cost function for three of the most important (cost-wise) diagnostic techniques and therapeutic services in Portuguese hospitals for the years 2002-06: Clinical Pathology, Medical Imaging and Physical Medicine and Rehabilitation. The estimation is carried out with a generalized translog cost function, assuming that hospitals operate in the short-run.

For Clinical Pathology and Medical Imaging, we find evidence of ray economies of scale, i.e. as we increase the quantity produced of each individual output, costs increase less than proportionally. For Physical Medicine and Rehabilitation, although a slightly different method was used, we also find that economies of scale appear to exist. We also find that there is evidence of economies of scope for some of the services provided within each category, but not for all of them. This suggests that some services could be provided independently within each hospital without affecting overall costs. For instance, in Clinical Pathology, we find little evidence of economies of scope between clinical chemistry - by far the most important (cost-wise) service within that category - and all other outputs. Thus, outsourcing the provision of that service would have almost no cost implications in the production of other outputs. By contrast, in Medical Imaging, computed tomography appears to exhibit scope economies with all other outputs except one (ultrasonography), which suggests that if computed tomography were to be outsourced, it would raise the costs of producing those other outputs.

These results have important policy implications and can be related to the ongoing discussion of where and how should hospitals provide these services. For instance, they allow us to assess whether the joint production of some services is more efficient than stand-alone production. In addition, and at the very least, the results contribute to a more informed view of the possible cost savings arising from aggregating production in fewer hospitals. Moreover, and in the context of the Portuguese National Health Service, the existence of economies of scale may provide a rationale for outsourcing particular services, even if they are to be provided by public or private 
contractors within the hospital premises. Such contractors could aggregate larger output levels and take advantage of such economies of scale. This possibility is enshrined in article 10 of Law $27 / 2002$, although, to the best of our knowledge, no Portuguese hospital has ever outsourced the provision of clinical services in such a way.

Finally, our results raise important questions associated with the estimated lower costs of service provision in Clinical Pathology and Medical Imaging by smaller (district and level 1) hospitals, even after adjusting for casemix. This may well be evidence that, as Coase (1937) suggested, central hospitals have surpassed their optimal size and are thus facing "diminishing returns to management". ${ }^{2}$ If that is the case, our results suggest that cost reductions could be achieved if central hospitals reorganized their provision of such services through the creation of smaller independent service-providing centres within the hospital.

The paper is organized in the following way: Section 2 presents the cost function to be estimated, whilst Section 3 describes the data used. Section 4 presents the results and Section 5 concludes. An appendix contains the data sources and the results of a restricted cost function model.

\section{The econometric setup}

The main economic concept at the heart of our analysis is the cost function. A firm's long-run cost function depends on the quantities produced of the various outputs $\left(y_{i}\right)$, as well as on the input prices $\left(w_{i}\right)$. Assuming there are $n$ outputs and $m$ inputs, a firm's long-run cost function is given by:

$$
C=C\left(y_{1}, \ldots, y_{n}, w_{1}, \ldots, w_{m}\right)
$$

The short-run is defined as a period of time which is too short for the firm to be able to change the quantity it uses of all its inputs. Typically, in the short-run there is at least one factor of production whose quantity the firm cannot easily change. If we define the quantity of this factor to be $k$, then a firm's short-run cost function will be given by:

$$
C^{S}=C^{S}\left(y_{1}, \ldots, y_{n}, w_{1}, \ldots, w_{m}, k\right)
$$

Because fixed factors of production necessarily lead to the existence of fixed costs, the short-run cost function can also be written as:

$$
C^{S}=V C\left(\mathbf{y}, \mathbf{w}_{v}, k\right)+F
$$

where $V C$ represents variable costs (i.e. costs associated with the inputs which the firm can vary in the short-run), $\mathbf{w}_{v}$ is the vector of all input prices except input $k, \mathbf{y}=\left(y_{1}, \ldots, y_{n}\right)$ is the

\footnotetext{
${ }^{2}$ Coase (1937), pp. 394-95.
} 
output vector and $F=w_{k} k$ is the fixed cost of production.

We make the assumption that hospitals operate in the short-run. This implies that we believe hospitals cannot easily change the quantity they use of all the factors of production, in response to a change in input prices or output levels. We use the generalized translog cost function to represent the variable cost function. This is a generalization of the translog cost function and it is appropriate when a significant number of observations has zero output levels: a Box-Cox transformation of the output levels is used instead of the usual (under the translog cost function) log-transformation. Therefore, output levels $y_{i}$ are transformed into $Y_{i}=\frac{y_{i}^{\lambda}-1}{\lambda} .3$ Similarly to other flexible functional forms, such as the quadratic cost function or the translog cost function, the generalized translog cost function represents a second-order Taylor approximation to the true (but unknown) functional form of a differentiable cost function. The equation representing it is:

$$
\begin{aligned}
\ln V C= & \alpha_{0}+\sum_{i=1}^{n} \beta_{i} Y_{i}+\frac{1}{2} \sum_{i=1}^{n} \sum_{j=1}^{n} \beta_{i j} Y_{i} Y_{j}+ \\
& +\sum_{i=1}^{m} \gamma_{i} \ln \left(w_{i}\right)+\frac{1}{2} \sum_{i=1}^{m} \sum_{j=1}^{m} \gamma_{i j} \ln \left(w_{i}\right) \ln \left(w_{j}\right)+\sum_{r=1}^{n} \sum_{i=1}^{m} \delta_{r i} \cdot Y_{r} \ln \left(w_{i}\right)+ \\
& +\beta_{K} \cdot \ln (k)+\frac{1}{2} \beta_{K K} \cdot(\ln (k))^{2}+\sum_{i=1}^{m} \sigma_{K i} \cdot \ln (k) \cdot \ln \left(w_{i}\right)+\sum_{i=1}^{n} \theta_{K i} \cdot \ln (k) \cdot Y_{i}
\end{aligned}
$$

We assume a symmetry constraint, $\beta_{i j}=\beta_{j i}$ and $\gamma_{i j}=\gamma_{j i}$, as well as linear homogeneity in input prices (i.e. doubling the price of all inputs leads to a doubling of costs):

$$
\begin{aligned}
\sum_{i=1}^{m} \gamma_{i} & =1 \\
\sum_{i=1}^{m} \delta_{r i} & =0, r=1, \ldots, n \\
\sum_{j=1}^{m} \gamma_{i j} & =0, i=1, \ldots, m \\
\sum_{i=1}^{m} \sigma_{K i} & =0
\end{aligned}
$$

Shephard's Lemma allows us to obtain the cost share equations through logarithmic differentiation of the cost function:

$$
S_{i}=\frac{\partial \ln V C}{\partial \ln w_{i}}=\gamma_{i}+\sum_{j=1}^{m} \gamma_{i j} \ln \left(w_{j}\right)+\sum_{r=1}^{n} \delta_{r i} \cdot Y_{r}+\sigma_{K i} \cdot \ln (k), i=1, \ldots, m
$$

\footnotetext{
${ }^{3}$ We assume $\lambda=0.1$. An earlier version of this paper (Gonçalves and Barros, 2009) shows that our results are robust to different values of $\lambda$.
} 
where $S_{i}=\frac{w_{i} \cdot x_{i}}{\sum_{i=1}^{m} w_{i} \cdot x_{i}}$ is the cost share of input $i\left(x_{i}\right.$ represents the quantity used of input $\left.i\right)$.

The Box-Cox transformation is applied to the output data $\left(y_{i}\right)$, but prior to that we mean-scale all our variables. ${ }^{4}$ As we will see, we identify two (variable) inputs for production: staff and other inputs, i.e. $m=2$. We then estimate the generalized translog cost function given by equations (4) and (6) in the following way: ${ }^{5}$

- Model 1: equations (4) and (6) were estimated with the homogeneity restrictions of equation (5) using Zellner's Seemingly Unrelated Regression (SUR) technique. Because the cost shares add up to unity, only one of them is independent. Therefore, the second cost share equation (associated with other variable inputs) was omitted from the regression.

- Model 2: similar to model 1, but only one input price was used - staff unit costs. In this scenario, the unit price of other variable inputs is implicitly used as the numeraire and therefore linear homogeneity is assumed to hold. Equations (4) and (6) were then estimated using Zellner's Seemingly Unrelated Regression (SUR) technique. Because the cost shares add up to unity, only one of them is independent. Therefore, the second cost share equation (associated with other variable inputs) was omitted from the regression.

Both models were estimated with pooled data, i.e. assuming that all observations were independent from one another.

\section{Data}

Portuguese hospitals in the National Health Service report their cost breakdown yearly to a central body (IGIF/ACSS). This cost breakdown allows for the identification of costs associated with the main hospital outputs (medical and surgical discharges, outpatient care, emergency room care, etc.), as well as with auxiliary services, such as diagnostic techniques and therapeutic services. ${ }^{6}$ These costs are further broken down by specialty and cost type (staff, materials and supplies, etc.). These could be viewed as "hospital disaggregated data", as they contain a breakdown of costs (by type) for specific hospital activities. As outlined earlier, our main interest was collecting data for

\footnotetext{
${ }^{4}$ For the fixed factor, $k$, for each output $y_{i}(i=1, \ldots, n)$ and for each input price $w_{j}(j=1, \ldots, m)$ we divide each observation by the respective mean, and hence the mean of the (new) mean-scaled variables is equal to 1 .

${ }^{5} \mathrm{~A}$ previous version of the paper (Gonçalves and Barros, 2009) estimates a second variant of each model under the assumption of homotheticity: as Smet (2002) notes, homotheticity implies that the mix of inputs which minimizes costs is not affected by the volume or even the mix of outputs and, therefore, changes in input prices will affect costs by a scale factor. In practice, homotheticity implies that $\delta_{r i}=0, \forall r, i$, in equation (4), i.e. input prices are not interacted with output levels. However, the homotheticity assumption is not rejected only for one model (Clinical Pathology, model 1) and we have focused instead on the results from the unrestricted (non-homothetic) models.

${ }^{6}$ The quantities produced by each hospital of the various outputs and/or diagnostic techniques and therapeutic services are also provided.
} 
three specialties within the auxiliary services - Clinical Pathology, Medical Imaging and Physical Medicine and Rehabilitation - as they have a significant weight in overall costs. ${ }^{7}$

In addition, we have collected "hospital aggregate data" related to the total number of staff in each hospital, the number of beds, the casemix index ${ }^{8}$ and total staff costs for each year. Some Portuguese public hospitals underwent a statutory transformation in 2005 and became "EPE" hospitals (public but autonomous hospitals of the National Health Service), as opposed to "SPA" hospitals (non-autonomous hospitals), and this changed the way aggregate hospital information was made public. ${ }^{9}$ Therefore, aggregate hospital data was obtained from a single source (the National Health Service reports) for the years 2002-2004, but from different sources for "EPE" and "SPA" hospitals for the years 2005-2006. Table 9 in Appendix A.1 summarizes the data sources used.

These data allowed us to calculate the main variables of interest for our cost function estimation. For each specialty (Clinical Pathology, Medical Imaging and Physical Medicine and Rehabilitation), variable costs were obtained by subtracting indirect costs and depreciation from total costs. Each specialties' output quantities were obtained directly from the sources in Table $9 .{ }^{10}$

We have assumed that diagnostic techniques and therapeutic services relied on the use of two variable inputs: staff and other inputs. Their prices were calculated indirectly. Staff unit costs $\left(w_{1}\right)$ were calculated by dividing total hospital staff costs by the total number of staff. Non-staff inputs are a composite of different categories of inputs - pharmaceutical products, clinical consumables and other expenses - whose costs are typically allocated to the respective categories on the basis of (possibly different across hospitals) accounting rules, which makes it advisable and less prone to error to consider them as an aggregate non-staff input. This, however, presents a problem in the (indirect) calculation of the respective price, because the (different) input quantities are not directly comparable. Therefore, we follow Garcia and Thomas (2001) and assume that the price of these non-staff inputs is represented by a unit cost $\left(w_{2}\right)$, which is calculated by dividing the total cost of non-staff related variable costs by the total quantity produced in each specialty. Therefore, the unit cost of other inputs is an imperfect measure for the price of other inputs, as it is expressed as a cost per unit of output.

In the short-run, we expect equipment to constitute a fixed factor of production, which hospitals could not easily (or rapidly) vary. However, we had no data available on hospital equipment used

\footnotetext{
${ }^{7}$ In 2004 , they accounted for $56 \%$ of the total costs of diagnostic techniques and therapeutic services.

${ }^{8}$ The casemix index for the years 2005 and 2006 for some "EPE" hospitals was not publicly available. In those cases, and because the casemix index does not change significantly over time, we have assumed that those hospitals' casemix index was equal to that of the most recently available year.

${ }^{9}$ The acronyms "EPE" and "SPA" stand for Entidade Pública Empresarial and Sector Público Administrativo respectively.

${ }^{10}$ Each output's weight in overall specialty costs varies significantly and within each specialty one output typically stands out in terms of its share of total costs. For instance, Clinical Chemistry is the output responsible for $57 \%$ of the total costs of Clinical Pathology. Similarly, Radiology accounts for some $74 \%$ of total Medical Imaging costs and Physical therapy accounts for $60 \%$ of total Physical Medicine and Rehabilitation costs. See Gonçalves and Barros (2009) for more details.
} 


\begin{tabular}{|c|c|c|c|c|c|c|c|c|}
\hline \multirow[b]{2}{*}{ Specialty } & \multirow[b]{2}{*}{ Variable description } & \multirow[b]{2}{*}{ Variable } & \multicolumn{2}{|c|}{ Descriptive statistics } & \multicolumn{4}{|c|}{ Number of observations } \\
\hline & & & Mean & St. Dev. & Total & $\begin{array}{l}0- \\
\text { observ. }\end{array}$ & $\begin{array}{l}\text { Positive } \\
\text { observ. }\end{array}$ & $\begin{array}{l}\text { Percentage of } \\
\text { observ. within } \\
0.5 \text { and } 1.5 \text { of } \\
\text { sample mean }\end{array}$ \\
\hline \multirow{12}{*}{$\begin{array}{c}\text { Clinical } \\
\text { Pathology }\end{array}$} & Variable costs $(€)$ & VC & $2,332,378$ & $3,019,846$ & 317 & - & - & - \\
\hline & Output: Clinical chemistry & $y_{1}$ & 654,030 & 814,234 & 317 & 7 & 310 & $40 \%$ \\
\hline & Output: Clinical hematology & $y_{2}$ & 120,629 & 357,442 & 317 & 141 & 176 & $17 \%$ \\
\hline & Output: Immunology & $y_{3}$ & 42,222 & 232,640 & 317 & 170 & 147 & $12 \%$ \\
\hline & Output: Clinical microbiology & $\mathrm{y}_{4}$ & 24,252 & 53,499 & 317 & 169 & 148 & $17 \%$ \\
\hline & Output: Endocrinology & $y_{5}$ & 7,934 & 58,952 & 317 & 280 & 37 & $1 \%$ \\
\hline & Output: Virology & $\mathrm{y}_{6}$ & 5,133 & 60,917 & 317 & 287 & 30 & $2 \%$ \\
\hline & Output: Clinical hematology/Hematoncology & $y_{7}$ & 23,762 & 171,947 & 317 & 300 & 17 & $1 \%$ \\
\hline & Input price: Staff unit costs $(€)$ & $\mathrm{w}_{1}$ & 26,681 & 4,516 & 317 & - & - & - \\
\hline & Input price: Non-staff unit costs $(€)$ & $\mathrm{w}_{2}$ & 1.88 & 1.16 & 317 & - & - & - \\
\hline & Fixed input: number of beds & $\mathrm{k}$ & 293.8 & 270.3 & 317 & - & - & - \\
\hline & Casemix index & Casemix & 1.04 & 0.33 & 317 & - & - & - \\
\hline \multirow{11}{*}{$\begin{array}{l}\text { Medical } \\
\text { Imaging }\end{array}$} & Variable costs $(€)$ & VC & $1,290,709$ & $1,598,582$ & 335 & - & - & - \\
\hline & Output: Radiology & $\mathrm{y}_{1}$ & 74,768 & 83,707 & 335 & 5 & 330 & $41 \%$ \\
\hline & Output: Angiography & $y_{2}$ & 1,202 & 12,304 & 335 & 288 & 47 & $3 \%$ \\
\hline & Output: Mamography & $y_{3}$ & 398 & 1,241 & 335 & 260 & 75 & $3 \%$ \\
\hline & Output: Computed tomography & $\mathrm{y}_{4}$ & 9,231 & 47,832 & 335 & 231 & 104 & $16 \%$ \\
\hline & Output: Ultrasonography & $\mathrm{y}_{5}$ & 6,110 & 11,083 & 335 & 154 & 181 & $19 \%$ \\
\hline & Output: Magnetic resonance imaging & $y_{6}$ & 1,358 & 12,746 & 335 & 304 & 31 & $1 \%$ \\
\hline & Input price: Staff unit costs $(€)$ & $\mathrm{w}_{1}$ & 26,478 & 4,552 & 335 & - & - & - \\
\hline & Input price: Non-staff unit costs $(€)$ & $\mathrm{w}_{2}$ & 5.54 & 6.35 & 335 & - & - & - \\
\hline & Fixed input: number of beds & k & 285.4 & 268.2 & 335 & - & - & - \\
\hline & Casemix index & Casemix & 1.05 & 0.34 & 335 & - & - & - \\
\hline \multirow{10}{*}{$\begin{array}{c}\text { Physical } \\
\text { Medicine \& } \\
\text { Rehabilitation }\end{array}$} & Variable costs $(€)$ & VC & 491,196 & 437,423 & 288 & - & - & - \\
\hline & Output: Electrotherapy & $\mathrm{y}_{1}$ & 33,954 & 110,782 & 288 & 212 & 76 & $4 \%$ \\
\hline & Output: Physical therapy & $y_{2}$ & 75,060 & 74,283 & 288 & 44 & 244 & $42 \%$ \\
\hline & Output: Hydro-kinesiotherapy & $y_{3}$ & 2,245 & 12,397 & 288 & 259 & 29 & $2 \%$ \\
\hline & Output: Occupational therapy & $\mathrm{y}_{4}$ & 3,831 & 16,920 & 288 & 240 & 48 & $4 \%$ \\
\hline & Output: Speech and language therapy & $\mathrm{y}_{5}$ & 1,636 & 13,161 & 288 & 237 & 51 & $6 \%$ \\
\hline & Input price: Staff unit costs $(€)$ & $\mathrm{w}_{1}$ & 26,549 & 4,675 & 288 & - & - & - \\
\hline & Input price: Non-staff unit costs $(€)$ & $w_{2}$ & 1.71 & 5.27 & 288 & - & - & - \\
\hline & Fixed input: number of beds & k & 307.1 & 275.0 & 288 & - & - & - \\
\hline & Casemix index & Casemix & 1.05 & 0.32 & 288 & - & - & - \\
\hline
\end{tabular}

Table 1: Descriptive statistics of the main variables used in the regressions

the number of beds as a proxy. It appears reasonable that available equipment for auxiliary medical services such as diagnostic techniques and therapeutic services is purchased as a function of the hospital dimension. The number of beds also captures the potential demand for the services, which are mostly provided to admitted patients.

Due to the variety of data sources used, some variables had a significant number of missing observations. Therefore, we have eliminated observations which reported missing or zero quantities when total costs were available ${ }^{11}$, observations with a missing casemix index and observations with missing total staff numbers. We have also not considered psychiatric hospitals and oncology hospitals. This has reduced the total number of observations available to 320 (from 357) for Clinical Pathology, to 335 (from 365) for Medical Imaging and to 288 (from 333) for Physical Medicine and

\footnotetext{
${ }^{11}$ In other words, we have not considered observations for which there was clearly misreported output production.
} 
Rehabilitation. In addition, the data on Clinical Pathology showed the presence of significant outliers at the top of the distribution. Therefore, the top $1 \%$ of the distribution (3 observations) was dropped, leaving us with 317 observations. Table 1 contains the descriptive statistics of the main variables used in our regressions.

In addition to the variables described earlier, we have expanded the model with additional dummy variables, related to the hospital type and location, as well as the year in question, all of which could explain differences in costs. ${ }^{12}$

\section{Results}

The results of the estimation of equation (4) are presented in Table 2. We only present the results for the cost function - the cost share equation improves the quality of the results, but its coefficients are (as we can see by looking at equations (4) and (6)) the same as in the cost function. Additionally, following the literature standard, we estimate and present all cost function coefficients.

As we can see, all the regressions present high values for $r^{2}$ and many individually insignificant t-ratios. This is a typical indication that multicollinearity is present, i.e. high correlations between explanatory variables. ${ }^{13}$ Whilst multicollinearity does not violate OLS assumptions (estimated coefficients remain unbiased), it does lead to larger standard errors, making it more difficult to find statistically significant coefficients. In order to analyse the issue, we have first looked at the "main" regression variables only: output levels $\left(Y_{i}, i=1, \ldots, n\right)$, input prices $\left(\ln \left(w_{j}\right), j=1,2\right)$ and the fixed input $(\ln (k))$. Firstly, looking only at pair-wise correlations among these variables, none suggested particular causes for concern. ${ }^{14}$ Secondly, for all specialties, these variables' variance-inflating factors (VIF) were low and the condition numbers were below standard thresholds above which multicollinearity is a concern. ${ }^{15,16}$ Clearly, multicollinearity is associated with the introduction of (i) non-linear variables (the square of each "main" variable) and (ii) interaction variables (each

\footnotetext{
${ }^{12}$ Portuguese hospitals are divided in three hierarchical categories: central, district and level 1 hospitals; therefore, a dummy variable was created taking on the value of 1 for the latter two categories (central hospitals were omitted): "D - district hospital" and "D - Level 1 hospital". There are 5 regions in Portugal and a dummy variable was created for four of those regions (the Alentejo region was omitted): "D - Region Algarve"; "D - Region Centro"; "D Region L. V. Tejo" (which includes Portugal's capital and largest city - Lisbon); "D - Region Norte" (which includes Portugal's second largest city - Porto). Finally, dummy variables were introduced for each year (except 2002, which was omitted): "D - 2003"; "D - 2004"; "D - 2005"; "D - 2006".

${ }^{13}$ We thank an anonymous referee for suggesting this line of analysis.

${ }^{14}$ For instance, Gujarati (1995, p. 335) suggests that correlations in excess of 0.8 may indicate collinearity, although such correlations are a necessary but not sufficient condition for its presence. The highest pair-wise correlation we have found between these variables (across specialties) was 0.81 .

${ }^{15}$ The variance-inflating factors inform us on how the variance of an estimator is inflated by the presence of multicollinearity (see Maddala, 1992, p. 274 or Gujarati, 1995, p. 328 for more details). VIFs above 10 are typically a sign that the variable is collinear. Looking only at these variables, none presents a VIF above 5, thus suggesting no multicollinearity problems.

${ }^{16}$ The condition number or index is an overall measure of multicollinearity and measures the sensitivity of regression estimates to small changes in the data (see Maddala, 1992, p. 274 for details). The condition numbers of these variables for each specialty were below 16 (values between 10 and 30 are indicative of moderate multicollinearity and above 30 multicollinearity is severe).
} 
"main" variable is interacted with every other "main" variable) in the regression, as suggested in equation (4). For instance, Gujarati (1995, p. 322) observes that powers of explanatory variables are typically highly correlated. As expected, once we analyse all the variables included in the estimation of equation (4), pair-wise correlations, VIFs and condition numbers all point to the presence of strong multicollinearity. As such, although estimated coefficients remain unbiased, standard errors are likely to be large.

This, however, is not a problem solely associated with the generalized translog cost function we estimate. Other second-order approximations of the cost function, such as the quadratic or translog functions, are also likely to be affected by multicollinearity, because all use powers and interactions of explanatory variables (output levels and input prices). For instance, Grannemann et al. (1986) use a hybrid functional form for the cost function which contains several variable interactions; ${ }^{17}$ Vitaliano (1987) notes that 30 out of 64 coefficients were not statistically significant because of multicollinearity problems. Therefore, multicollinearity should be viewed as the norm rather than the exception in cost function estimations.

If a second-order Taylor approximation to the true cost function, such as the quadratic, translog or generalized translog, is to be estimated, all that can realistically be done is to minimize the (negative) effects of multicollinearity. Gujarati (1995, p. 344) suggests that, in practice, when powers of explanatory variables are included in the regression, expressing the variables as deviations from their means alleviates the multicollinearity problem. Hence, our mean-scaling of the variables should be helpful in this context. Gujarati (1995, p. 340) also suggests imposing a priori restrictions (which theoretically are expected to hold) on the regression coefficients. Therefore, the homogeneity assumptions imposed on our estimation (equation (5)) are also likely to contribute towards minimizing the impact of multicollinearity. Finally, using Zellner's SUR technique (instead of OLS) is also likely to be "... especially fruitful when multicollinearity problems are encountered..." (Binkley, 1982, p. 890) because "... the greater the multicollinearity within an equation, the more likely is SUR to lead to significant efficiency gains [compared with OLS]" (Binkley, 1982, p. 894).

An often used solution in the presence of multicollinearity is to drop one (or several) collinear variables. However, in doing so we may be committing a specification bias (Gujarati, 1995, p. 341) by (erroneously) excluding relevant variables and leading our estimates to be biased. As Gujarati (1995, p. 342) observes, "...the remedy may be worse than the disease in some situations because, whereas multicollinearity may prevent precise estimation of the parameters of the model, omitting a variable may seriously mislead us as to the true values of the parameters". For completeness, we report the results of a restricted version of the cost function for each specialty (see Table 10 in Appendix A.2), obtained through a stepwise regression approach. Overall, the estimated coefficients

\footnotetext{
${ }^{17}$ The ad-hoc specification adopted is a mixture of a translog (costs and input prices enter the regression in logarithms) and a quadratic cost function (outputs do not enter the regression in logs because of zero output levels).
} 


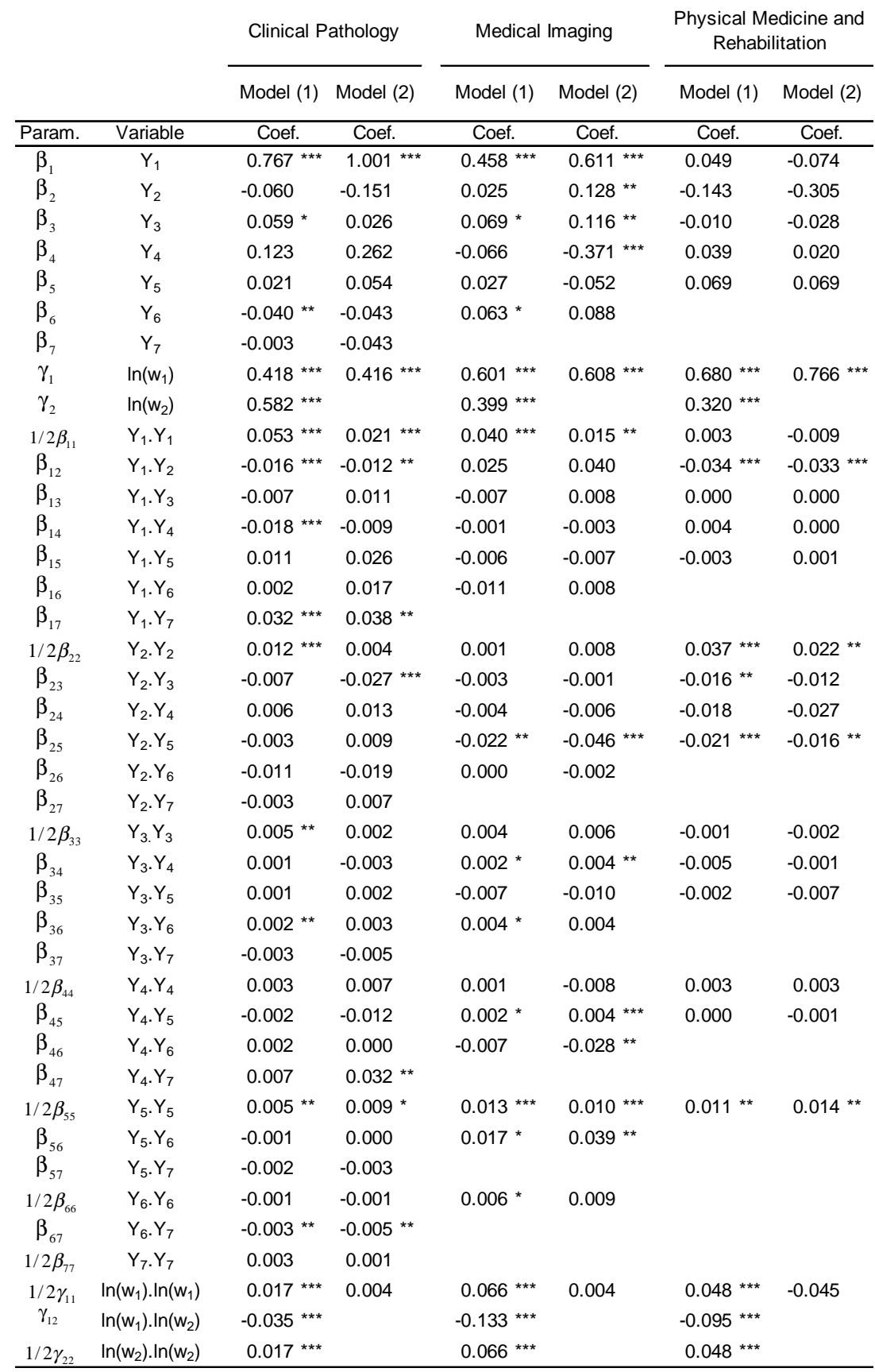

$\left({ }^{\star \star \star}\right)$ Significant at the $1 \%$ level; $\left(^{\star \star}\right)$ Significant at the $5 \%$ level; $\left(^{*}\right)$ Significant at the $10 \%$ level Note: For a quick reference on the variables' definition, see Table 1.

Table 2: Estimation results 


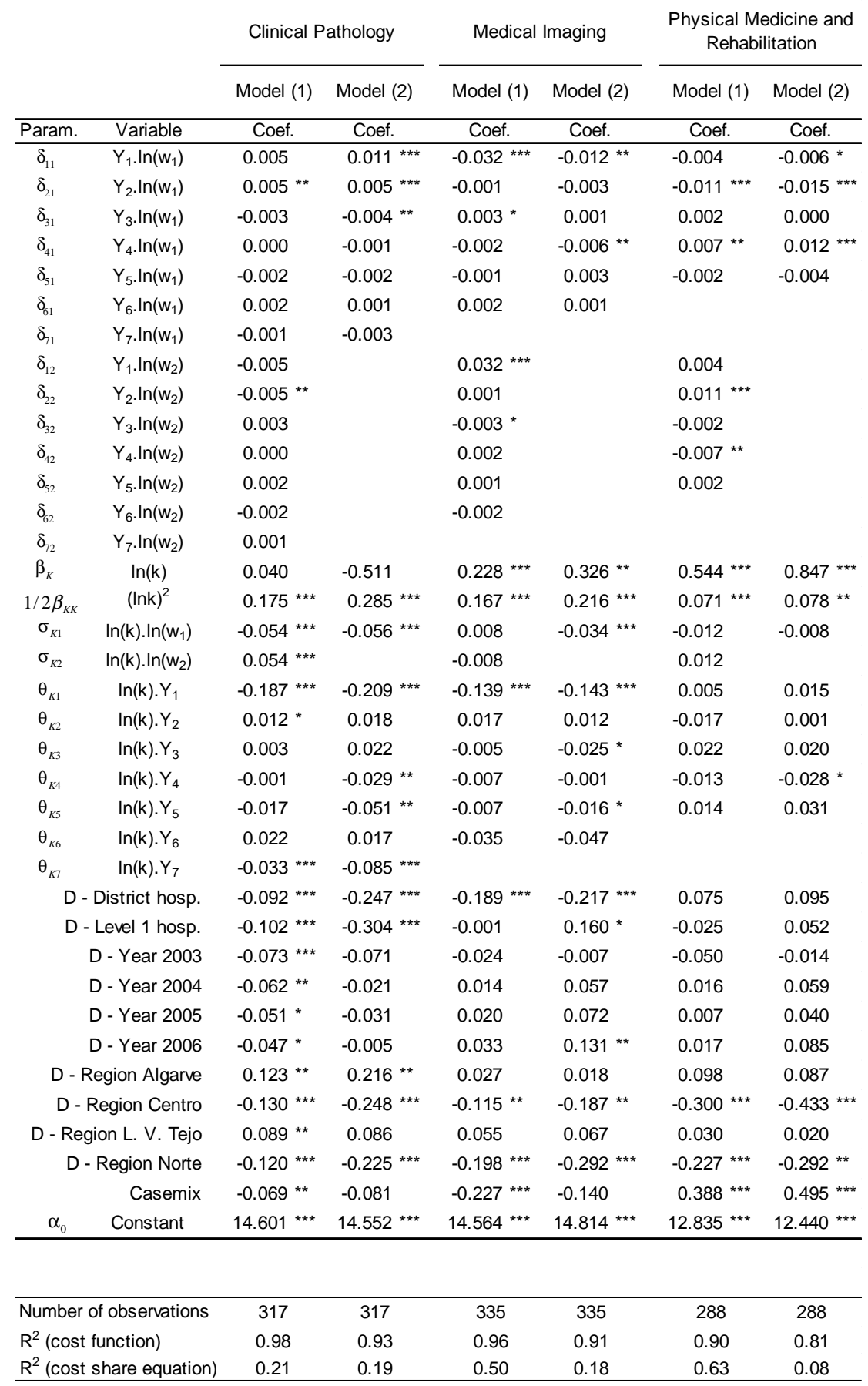

$\left({ }^{\star \star \star}\right)$ Significant at the $1 \%$ level; $\left({ }^{\star \star}\right)$ Significant at the $5 \%$ level; $\left({ }^{\star}\right)$ Significant at the $10 \%$ level Note: For a quick reference on the variables' definition, see Table 1.

Table 2 (cont.): Estimation results 
differ significantly from those in Table 2, quite possibly because of the specification bias. ${ }^{18}$

We have also looked at two other potential problems in our regression results: heteroskedasticity and autocorrelation. Heteroskedasticity exists when the error term does not have a constant variance (i.e. when it is not homoskedastic). Although heteroskedasticity does not result in biased parameters, it invalidates the use of estimated standard errors for hypothesis testing. ${ }^{19}$ Firstly, we performed a visual inspection of the squared residuals plotted against the fitted values in order to detect any systematic patterns, although none were found. ${ }^{20}$ We then tested for the existence of heteroskedasticity by using a RESET test. ${ }^{21}$ At the $1 \%$ significance level, we could not reject the hypothesis of homoskedasticity. ${ }^{22}$

Autocorrelation is a typical problem in time series data, where the error term in one period is correlated with the error term in previous or subsequent periods. Although the estimated parameters remain unbiased in its presence, the estimated standard errors are larger. The data used in our estimation does not consist of time series. Instead, it is an (unbalanced) panel, where every variable is observed for each hospital over time. As Cameron and Trivedi (2005) note, an autocorrelation problem exists with this type of data if the errors are correlated over time for a given "individual" (in our case, hospitals). This can be corrected by introducing individual or group-specific dummies as well as time dummies. As outlined above, this is the approach we have adopted and it appears to have corrected the problem: an analysis of the correlation of residuals over time for each hospital does not suggest the existence of autocorrelation. ${ }^{23}$

\subsection{Economies of scale}

Ray economies of scale, in a multiproduct cost function setting, refer to the proportional increase in total costs which result from a proportional increase in all the outputs. Alternatively, viewed from the production function perspective, ray economies of scale refer to the proportional increase in outputs which result from proportional increases in the quantity used of all inputs. Inevitably, any concept of economies of scale implicitly refers to the long run. Vita (1990) points out that

\footnotetext{
${ }^{18}$ The standard approach of estimating the full cost function and presenting all the estimated coefficients, as in Table 2, may also be justified because the coefficients remain unbiased even in the presence of multicollinearity.

${ }^{19}$ See Maddala (1992, pp. 209-211) for more details.

${ }^{20}$ Gujarati (1995, p. 368) suggests that such informal methods are useful to detect the possible existence of a relationship between the fitted values and the residuals, thus informing us on the type of heteroskedasticity that may be present.

${ }^{21}$ The RESET test (see Maddala, 1992, p. 204 for more details) consists of regressing $\hat{u}$ (the estimated residuals) on $\hat{y}^{2}$ and $\hat{y}^{3}$, where $\hat{y}$ are the fitted values, and testing whether the respective coefficients are significant (in which case the hypothesis of homoskedasticity would be rejected).

${ }^{22}$ The hypothesis of homoskedasticity could not be rejected (for all models and specialties) at the $1 \%$ significance level. It would be rejected at the $5 \%$ significance level for Physical Medicine and Rehabilitation (model 1) and at the $10 \%$ significance level for Clinical Pathology (model 1).

${ }^{23}$ Within each hospital, and for all specialties and models, we have looked at the correlation between the residual at time $t$ and at time $t-1$. For Clinical Pathology ( 81 hospitals) and Medical Imaging ( 83 hospitals), no correlation is significant at the $1 \%$ significance level; for Physical Medicine and Rehabilitation (74 hospitals), one correlation (in model 2) is significant at the $1 \%$ level.
} 
when a variable cost function is estimated, ray economies of scale (RTS) can be calculated in the following way (see also Braeutigam and Daughety, 1983):

$$
R T S=\frac{1-\frac{\partial \ln V C}{\partial \ln \left(k^{*}\right)}}{\sum_{i=1}^{n} \eta_{i}}
$$

where $\eta_{i}$ is the cost elasticity of output $i$ :

$$
\eta_{i}=\frac{\partial C}{\partial y_{i}^{*}} \frac{y_{i}^{*}}{C}
$$

$\eta_{i}$ represents the percent change in costs when output $i$ varies by $1 \%$. In our case, and similarly to Vita (1990), the cost elasticity of output $i$ is given by:

$$
\eta_{i}=\left(\beta_{i}+\sum_{j=1}^{n} \beta_{i j} Y_{j}+\sum_{j=1}^{m} \delta_{i j} \ln \left(w_{j}\right)+\theta_{K i} \ln (k)\right) y_{i}^{\lambda}
$$

where $y_{i}$ is the untransformed output and $\lambda$ represents the Box-Cox parameter used in the transformation. At the sample mean, because we have mean scaled our data prior to the Box-Cox transformation, the cost elasticity of output $i$ is simply given by $\eta_{i}=\beta_{i}$, where $\beta_{i}$ is the output parameter from the estimated cost function (equation (4)). An estimate of RTS in equation (7) larger than one indicates the existence of economies of scale. In particular, an increase of all the outputs in an average hospital by $1 \%$ would increase variable costs by $1 / R T S$ percent.

In equation (7), $k^{*}$ should ideally represent the optimal level for the fixed factor. However, the calculation of this optimal level for the fixed factor would require the use of input price data which we do not possess. Therefore, we follow the approach suggested by Caves et al. (1981), and use the actual level of the fixed factor (instead of the optimal level) when computing equation (7). As Vita (1990, p. 15) notes, this method "...evaluates scale economies along a ray from the origin that passes through the actual point of operation observed in the sample". Since we are estimating a variable cost function, we are implicitly assuming that firms are not operating on their efficient expansion path, i.e. they are not using the optimal level of the fixed factor. Therefore, it is likely that the two methods for computing equation (7) would yield different results. ${ }^{24}$

As we can see from the estimates of $R T S$ (equation (7)) at the sample mean presented in Table 3 , ray economies of scale appear to exist: for either model, and for Clinical Pathology and Medical Imaging, the estimates of RTS are statistically significant and larger than one. ${ }^{25}$ In addition, we have tested the hypothesis of constant returns to scale $(R T S=1)$. The hypothesis is rejected for Clinical Pathology (model 2) and Medical Imaging (model 1). However, care should be taken in the

\footnotetext{
${ }^{24}$ See Vita (1990) for a more detailed discussion.

${ }^{25}$ In the calculation of RTS (according to equation (7)) all the relevant coefficients are used (even statistically insignificant ones). As discussed earlier, the presence of multicollinearity causes the coefficients' standard errors to be larger, but their estimates remain unbiased.
} 


\begin{tabular}{|c|c|c|c|c|c|c|}
\hline \multirow[t]{2}{*}{ Ray economies of scale } & \multicolumn{3}{|c|}{ Model (1) } & \multicolumn{3}{|c|}{ Model (2) } \\
\hline & RTS & (std. error) & $\mathrm{H}_{0}: \mathrm{RTS}=1$ & RTS & (std. error) & $\mathrm{H}_{0}: \mathrm{RTS}=1$ \\
\hline Clinical Pathology & 1.11 & $(0.09)$ & & 1.37 & $(0.14)$ & *** \\
\hline Medical Imaging & 1.34 & $(0.19)$ & * & 1.30 & $(0.34)$ & \\
\hline
\end{tabular}

Table 3: Ray economies of scale

\begin{tabular}{lcccccc} 
Ray economies of scale & \multicolumn{2}{c}{ Clinical Pathology } & & \multicolumn{2}{c}{ Medical Imaging } \\
\cline { 2 - 3 } \cline { 5 - 6 } & Model (1) & Model $(2)$ & & Model (1) & Model (2) \\
\hline All $Y_{i} 20 \%$ above sample mean & 1.05 & 1.30 & & 1.27 & 1.24 \\
All $Y_{i} 10 \%$ above sample mean & 1.08 & 1.33 & & 1.30 & 1.27 \\
At sample mean (all variables) & 1.11 & 1.37 & & 1.34 & 1.30 \\
All $Y_{i} 10 \%$ below sample mean & 1.14 & 1.41 & & 1.38 & 1.33 \\
All $Y_{i} 20 \%$ below sample mean & 1.17 & 1.45 & & 1.43 & 1.36 \\
\hline
\end{tabular}

Table 4: Ray economies of scale above and below sample mean

interpretation of these results. Because of multicollinearity (discussed earlier), coefficients' standard errors are likely to be large. Hence, when testing hypotheses using those coefficients (e.g. significance tests, as well as tests of linear or non-linear combinations), rejection of the null constitutes strong evidence against it, whilst non-rejection may be caused by the large standard errors, a point also made by Fraquelli et al. (2004, p. 2057). Because of this, previous work looks mainly at the estimate of RTS in order to determine whether ray economies of scale exist. ${ }^{26}$

For Clinical Pathology and Medical Imaging, we have also calculated the returns to scale indicator for different levels of output (assuming all other variables are at the sample mean, including the number of beds). Table 4 presents those estimates. Rather importantly, we can see that ray economies of scale are less pronounced as we increase the level of output above the sample mean. This is to be expected, as an increase of all output levels would partly exhaust the existing economies of scale. The reverse is true when we decrease the output levels below the sample mean.

For Physical Medicine and Rehabilitation, the estimates of $R T S$ at the sample mean are implausible and exhibit a wide variability across models. Our conjecture is that the sample mean for all outputs may not be the most appropriate scale to evaluate ray economies of scale in this specialty. Looking at Table 1, we can see that in Clinical Pathology and Medical Imaging a significant percentage of observations (more than 10\%) contains output production within 0.5 and 1.5 of the sample mean, and this is true for several outputs. By contrast, in Physical Medicine and Rehabilitation, output production within 0.5 and 1.5 of the sample mean is only considerable for physical therapy; for all other outputs, there is a large number of 0-observations and few (less than $6 \%)$ are within that interval.

\footnotetext{
${ }^{26}$ See, for instance, Cowing and Holtmann (1983) or Vita (1990).
} 


\begin{tabular}{llcc} 
Ray economies of scale (individual observations) & \multicolumn{2}{c}{ RTS } \\
\cline { 3 - 4 } & & Model (1) & Model (2) \\
\hline Clinical Pathology & Median - per observation & 1.24 & 1.70 \\
& Median - per hospital & 1.20 & 1.63 \\
Medical Imaging & Median - per observation & 1.13 & 1.05 \\
& Median - per hospital & 1.12 & 0.95 \\
Physical Medicine and Rehabilitation & Median - per observation & 1.22 & 1.28 \\
& Median - per hospital & 1.23 & 1.23 \\
\hline
\end{tabular}

Table 5: Ray economies of scale - individual observations

Therefore, we have used the estimated coefficients presented in Table 2 to calculate an RTS estimate for each observation (i.e. for each hospital and year). In other words, we have estimated $R T S$ (equation (7)) using the actual level of the explanatory variables associated with each observation. Naturally, such estimates must be interpreted with caution because, as Vita (1990) notes, estimated flexible cost functions perform poorly when evaluated away from the approximation point. Nevertheless, and in order to correct this problem, we present in Table 5 the median of all individually calculated $R T S$ estimates. ${ }^{27}$ In addition, we have also calculated the mean $R T S$ estimate for each hospital (each hospital may have a different number of observations in the panel) and then calculated the median of such hospitals' RTS estimates.

Firstly, notice that the estimates for Clinical Pathology and Medical Imaging are not too different from those presented in Table 3: for Clinical Pathology, these estimates are slightly larger, whereas for Medical Imaging they are slightly lower. Nevertheless, with one single exception (median per hospital of Medical Imaging) they all suggest the existence of economies of scale in these two specialties. As for Physical Medicine and Rehabilitation, the RTS estimates presented in Table 3 also suggest the existence of economies of scale. More importantly, such estimates do not vary significantly across models or depending on the calculation method (median per observation or median per hospital) and range from 1.22 to 1.28 .

\subsection{Economies of scope}

Economies of scope are said to exist if the joint costs of producing the various outputs are lower than the cost of producing those outputs separately. For instance, in a three-output case, overall economies of scope (ES) are given by:

$$
E S=\frac{C\left(y_{1}, 0,0\right)+C\left(0, y_{2}, 0\right)+C\left(0,0, y_{3}\right)-C\left(y_{1}, y_{2}, y_{3}\right)}{C\left(y_{1}, y_{2}, y_{3}\right)}
$$

As Vita (1990) points out, one could evaluate this expression using the estimated cost function.

\footnotetext{
${ }^{27}$ Our results indicate that the mean of the individually estimated RTS estimates is heavily influenced by very high and very low RTS estimates, which are clearly related to their distance from the approximation point. Therefore, we have chosen to present the median of such estimates, which is not influenced by their magnitude.
} 
However, flexible cost functions such as the one in equation (4) do not typically provide plausible cost estimates when evaluated at zero output levels. Therefore, Vita (1990) tests for the existence of weak cost complementarities (WCC) at the point of approximation of the cost function, which are a sufficient condition for economies of scope to exist. Following Vita (1990), weak cost complementarities exist if the following expression is negative:

$$
\begin{aligned}
C_{i j} & =C_{v i j}+C_{v j K} \cdot \frac{\partial k^{*}}{\partial y_{j}} \\
& =\frac{\partial^{2} V C}{\partial y_{i} \partial y_{j}}+\frac{\partial^{2} V C}{\partial y_{j} \partial k} \frac{\partial k^{*}}{\partial y_{j}}
\end{aligned}
$$

This decomposition is due to Cowing and Holtmann (1983). If $\frac{\partial k^{*}}{\partial y_{j}}>0$, then $k$ is a normal input and a sufficient condition for $C_{i j}$ to be negative is that $C_{v i j}=\frac{\partial^{2} V C}{\partial y_{i} \partial y_{j}}<0$ and $C_{v j K}=\frac{\partial^{2} V C}{\partial y_{j} \partial k}<0$. Again following Vita (1990), for the former to be verified, it must be true that $\beta_{i} \beta_{j}+\beta_{i j}<0$ (parameters in equation (4)); for the latter to be true, $\theta_{K j}<0$ must be verified.

Tables 6, 7 and 8 present the estimates of $C_{v i j}$ and $C_{v j K}$ for all possible output combinations and for Clinical Pathology, Medical Imaging and Physical Medicine and Rehabilitation respectively, as well as their statistical significance. The columns further to the right in each of those Tables assesses whether weak cost complementarities exist according to two criteria: a first (less stringent) criteria demands that both $C_{v i j}$ and $C_{v j K}$ be negative (regardless of their statistical significance); a second (more stringent) criteria demands that at least one estimate be negative and statistically significant, whilst the other must be either negative (and significant) or insignificant. ${ }^{28}$ Looking at a two-output combination, if these two criteria are satisfied across models, we define this to be strong evidence of weak cost complementarities between those outputs; however, if only the less stringent criteria is satisfied across models, whilst the more stringent criteria is satisfied for one model only, we define this to be suggestive evidence of weak cost complementarities.

Starting with Clinical Pathology (Table 6), there is strong evidence of weak cost complementarities between outputs 3 and 7 (immunology and clinical hematology/hematoncology), outputs 5 and 7 (endocrinology and clinical hematology/hematoncology) and outputs 6 and 7 (virology and clinical hematology/hematoncology): in all these cases, the estimates of $C_{v i j}$ and $C_{v j K}$ satisfy both criteria outlined above for both models. There is also suggestive evidence of weak cost complementarities between outputs 2 and 4 (clinical hematology and clinical microbiology) and 2 and 7 (clinical hematology and clinical hematology/hematoncology). ${ }^{29}$

\footnotetext{
${ }^{28}$ As mentioned earlier, multicollinearity causes standard errors to be large, thus making it more difficult to find statistically significant estimates for $C_{v i j}$ and $C_{v j K}$.

${ }^{29}$ One could also conclude there to be suggestive evidence of weak cost complementarities between outputs 1 and 7 (clinical chemistry and clinical hematology/hematoncology) and 4 and 7 (clinical microbiology and clinical hematology/hematoncology), insofar as the coefficients satisfy the more stringent criteria (but not the less stringent criteria) across models.
} 


\begin{tabular}{|c|c|c|c|c|c|c|c|c|}
\hline \multirow[b]{2}{*}{ Outputs: } & \multicolumn{2}{|c|}{ Model (1) } & \multicolumn{2}{|c|}{ Model (2) } & \multicolumn{2}{|c|}{$\begin{array}{c}C_{v i j}<0 \\
\text { and } \\
C_{v j K}<0\end{array}$} & \multicolumn{2}{|c|}{ 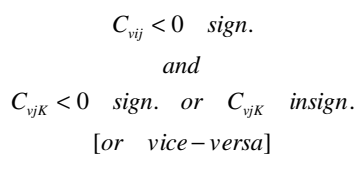 } \\
\hline & $C_{v i j}$ & $C_{v j K}$ & $C_{v i j}$ & $C_{v j K}$ & $\frac{{ }^{y / N}}{(1)}$ & (2) & (1) & (2) \\
\hline 1 and 2 & -0.063 & 0.012 * & -0.163 & 0.018 & & & & \\
\hline 1 and 3 & 0.038 & 0.003 & 0.038 & 0.022 & & & & \\
\hline 1 and 4 & 0.077 & -0.001 & 0.253 & -0.029 ** & & & & yes \\
\hline 1 and 5 & 0.027 & -0.017 & 0.080 & $-0.051^{* \star}$ & & & & yes \\
\hline 1 and 6 & -0.029 & 0.022 & -0.026 & 0.017 & & & & \\
\hline 1 and 7 & 0.030 & $-0.033^{\star \star *}$ & -0.006 & $-0.085^{\star \star \star *}$ & & yes & yes & yes \\
\hline 2 and 3 & -0.010 & 0.003 & $-0.031^{* *}$ & 0.022 & & & & yes \\
\hline 2 and 4 & -0.002 & -0.001 & -0.027 & -0.029 ** & yes & yes & & yes \\
\hline 2 and 5 & -0.004 & -0.017 & 0.001 & $-0.051^{\star *}$ & yes & & & yes \\
\hline 2 and 6 & -0.009 & 0.022 & -0.013 & 0.017 & & & & \\
\hline 2 and 7 & -0.003 & $-0.033^{* * *}$ & 0.014 & $-0.085^{* * *}$ & yes & & yes & yes \\
\hline 3 and 4 & 0.008 & -0.001 & 0.004 & $-0.029 * *$ & & & & yes \\
\hline 3 and 5 & 0.002 & -0.017 & 0.003 & $-0.051^{\star \star}$ & & & & yes \\
\hline 3 and 6 & 0.000 & 0.022 & 0.002 & 0.017 & & & & \\
\hline 3 and 7 & -0.003 & $-0.033^{* \star *}$ & -0.006 & $-0.085^{* * *}$ & yes & yes & yes & yes \\
\hline 4 and 5 & 0.001 & -0.017 & 0.002 & $-0.051^{\star \star}$ & & & & yes \\
\hline 4 and 6 & -0.003 & 0.022 & -0.011 & 0.017 & & & & \\
\hline 4 and 7 & 0.007 & $-0.033^{* * *}$ & 0.021 & $-0.085^{* * *}$ & & & yes & yes \\
\hline 5 and 6 & -0.002 & 0.022 & -0.002 & 0.017 & & & & \\
\hline 5 and 7 & -0.002 & $-0.033^{\star \star \star}$ & -0.005 & $-0.085^{* * *}$ & yes & yes & yes & yes \\
\hline 6 and 7 & $-0.003^{* *}$ & $-0.033^{\star \star \star}$ & -0.003 & $-0.085^{* * *}$ & yes & yes & yes & yes \\
\hline
\end{tabular}

Table 6: Weak Cost Complementarities - Clinical Pathology

Following the same approach for Medical Imaging (Table 7), there is strong evidence that outputs 2 and 5 (angiography and ultrasonography), as well as suggestive evidence that outputs 1 and 4 (radiology and computed tomography), outputs 2 and 4 (angiography and computed tomography), outputs 3 and 5 (mamography and ultrasonography), and outputs 4 and 6 (computed tomography and magnetic resonance imaging), exhibit weak cost complementarities. ${ }^{30}$

For Physical Medicine and Rehabilitation (Table 8), because of the large standard errors of the coefficients (see Table 2), we find only suggestive evidence of weak cost complementarities between outputs 2 and 4 (physical therapy and occupational therapy) and outputs 3 and 4 (hydrokinesiotherapy and occupational therapy).

These findings have some policy implications for outsourcing decisions. In Clinical Pathology, notice that there is little evidence of economies of scope between clinical chemistry - by far the most important (cost-wise) service in that specialty - and all other outputs (except output 7). Similarly, in Physical Medicine and Rehabilitation, output 5 (speech and language therapy) does not appear

\footnotetext{
${ }^{30}$ One could also argue that there may be some evidence of economies of scope between outputs 3 and 4 (mamography and computed tomography), insofar as the less stringent criteria is satisfied for both models.
} 


\begin{tabular}{|c|c|c|c|c|c|c|c|c|}
\hline \multirow[b]{2}{*}{ Outputs: } & \multicolumn{2}{|c|}{ Model (1) } & \multicolumn{2}{|c|}{ Model (2) } & \multicolumn{2}{|c|}{$\begin{array}{c}C_{v i j}<0 \\
\text { and } \\
C_{v j K}<0\end{array}$} & \multicolumn{2}{|c|}{$\begin{array}{c}C_{v i j}<0 \quad \text { sign. } \\
\text { and }\end{array}$} \\
\hline & $C_{v i j}$ & $C_{v j K}$ & $C_{v i j}$ & $C_{v j K}$ & (1) & (2) & (1) & (2) \\
\hline 1 and 2 & 0.037 & 0.017 & $0.118^{* *}$ & 0.012 & & & & \\
\hline 1 and 3 & 0.024 & -0.005 & 0.079 & -0.025 * & & & & yes \\
\hline 1 and 4 & -0.031 & -0.007 & -0.229 ** & -0.001 & yes & yes & & yes \\
\hline 1 and 5 & 0.006 & -0.007 & -0.038 & -0.016 * & & yes & & yes \\
\hline 1 and 6 & 0.018 & -0.035 & 0.062 & -0.047 & & & & \\
\hline 2 and 3 & -0.001 & -0.005 & 0.014 & -0.025 * & yes & & & yes \\
\hline 2 and 4 & -0.005 & -0.007 & -0.054 * & -0.001 & yes & yes & & yes \\
\hline 2 and 5 & -0.021 ** & -0.007 & $-0.052^{* * *}$ & -0.016 * & yes & yes & yes & yes \\
\hline 2 and 6 & 0.002 & -0.035 & 0.009 & -0.047 & & & & \\
\hline 3 and 4 & -0.002 & -0.007 & -0.039 & -0.001 & yes & yes & & \\
\hline 3 and 5 & -0.005 & -0.007 & -0.016 & -0.016 * & yes & yes & & yes \\
\hline 3 and 6 & 0.009 * & -0.035 & 0.014 & -0.047 & & & & \\
\hline 4 and 5 & 0.000 & -0.007 & 0.023 & -0.016 * & & & & yes \\
\hline 4 and 6 & -0.011 & -0.035 & -0.061 * & -0.047 & yes & yes & & yes \\
\hline 5 and 6 & 0.019 * & -0.035 & 0.035 * & -0.047 & & & & \\
\hline
\end{tabular}

Table 7: Weak Cost Complementarities - Medical Imaging

\begin{tabular}{|c|c|c|c|c|c|c|c|c|}
\hline \multirow[b]{2}{*}{ Outputs: } & \multicolumn{2}{|c|}{ Model (1) } & \multicolumn{2}{|c|}{ Model (2) } & \multicolumn{2}{|c|}{$\begin{array}{c}C_{v i j}<0 \\
\text { and } \\
C_{v j K}<0\end{array}$} & \multicolumn{2}{|c|}{$\begin{array}{l}C_{v i j}<0 \text { sign. } \\
\text { and } \\
0 \text { sign. or } C_{v j K} \text { insign. } \\
{\left[\begin{array}{l}\text { or vice-versa }]\end{array}\right.}\end{array}$} \\
\hline & $C_{v i j}$ & $C_{v j K}$ & $C_{v i j}$ & $C_{v j K}$ & (1) & (2) & (1) & (2) \\
\hline 1 and 2 & $-0.041^{* * *}$ & -0.017 & -0.010 & 0.001 & yes & & yes & \\
\hline 1 and 3 & -0.001 & 0.022 & 0.002 & 0.020 & & & & \\
\hline 1 and 4 & 0.006 & -0.013 & -0.002 & -0.028 * & & yes & & yes \\
\hline 1 and 5 & 0.000 & 0.014 & -0.004 & 0.031 & & & & \\
\hline 2 and 3 & $-0.014^{* *}$ & 0.022 & -0.003 & 0.020 & & & yes & \\
\hline 2 and 4 & -0.023 & -0.013 & -0.033 & -0.028 * & yes & yes & & yes \\
\hline 2 and 5 & -0.030 ** & 0.014 & -0.037 & 0.031 & & & yes & \\
\hline 3 and 4 & -0.005 & -0.013 & -0.002 & -0.028 * & yes & yes & & yes \\
\hline 3 and 5 & -0.002 & 0.014 & -0.009 & 0.031 & & & & \\
\hline 4 and 5 & 0.003 & 0.014 & 0.000 & 0.031 & & & & \\
\hline
\end{tabular}

Table 8: Weak Cost Complementarities - Physical Medicine and Rehabilitation 
to exhibit any cost complementarities with other outputs. In both cases, this suggests that these outputs could be independently provided without affecting their respective specialties' overall costs. By contrast, in Medical Imaging, computed tomography appears to exhibit scope economies with all other outputs except one (ultrasonography), which suggests that if computed tomography were to be outsourced, it would raise the costs of producing those other outputs.

\subsection{Diminishing returns to management}

The results for Clinical Pathology and Medical Imaging (see Table 2) suggests that smaller hospitals (district hospitals in both cases and level 1 hospitals for Clinical Pathology) have lower costs, even after adjusting for output production, input prices and other factors, such as the casemix. Therefore, for a given scale of production, producing in those hospitals is less expensive than producing in larger (central) hospitals (ceteris paribus). One possible explanation for this result could be related to the existence and/or importance of emergency care in each hospital. For instance, one might argue that hospitals where emergency care patients have a higher weight compared to inpatients or outpatients may justify higher costs, for instance, because of overtime expenses or because of the need to operate medical equipment for longer hours. ${ }^{31}$ We have thus investigated whether the inclusion of such variables in the estimation of equations (4) and (6) affected our results. ${ }^{32}$ Broadly speaking, and according to our data, the weight of emergency room care is lower in larger (central) hospitals and we find such a weight to be either negative or statistically insignificant in the estimation of equations (4) and (6). In other words, whilst believing that a higher weight of emergency room care could explain higher costs, we have found that the opposite may hold: when the coefficients are significant, smaller hospitals have lower costs precisely because their weight of emergency room care is larger. This implies that our result - that larger hospitals have, ceteris paribus, higher costs - holds even when one considers other possibly relevant variables such as the relative importance of emergency room care in each hospital.

These results raise important questions which go beyond the identification of economies of scale. Coase (1937), when discussing the limits of firm size, observes that as firms get larger, the costs of organizing additional transactions within the firm may increase and that managers may fail to make the best use of the production factors (inefficiency). ${ }^{33}$ Both factors may explain why a single firm does not carry out all production and why outsourcing becomes a reasonable decision once a certain scale of production is reached. In this context, and at the very least, our results indicate that the way in which production is organized in smaller hospitals yields lower costs for a given scale of production. Alternatively, our results suggest that central hospitals may have surpassed their optimal size and are thus facing "diminishing returns to management" (Coase, 1937). If

\footnotetext{
${ }^{31}$ And this may imply higher maintenance costs.

${ }^{32}$ We omit the results from the paper but we are happy to provide them upon request.

${ }^{33}$ Coase (1937), pp. 394-395.
} 
outsourcing were to be decided, these hospitals would be the more likely candidates to benefit from using the market as a resource allocation mechanism. Or, alternatively, it would make sense to create smaller but independent production centres within larger hospitals, which could thus better replicate the (lower cost) organization of production of smaller hospitals.

\section{Conclusion}

This paper has addressed a yet under-researched topic: the provision of services within hospitals, particularly auxiliary clinical services. Because such services have a significant weight in total hospital costs, a proper analysis of their cost structure is warranted. In particular, it is important to analyse the arguments which should underlie the make-or-buy decisions that hospitals must make regarding the provision of these services. Clearly, the possible existence of economies of scale and scope is essential in order to understand whether hospitals are better off through in-house production or through outsourcing.

We estimate a flexible cost function (generalized translog) for three of the most important (costwise) diagnostic techniques and therapeutic services in Portuguese hospitals (Clinical Pathology, Medical Imaging and Physical Medicine and Rehabilitation) and find there to be ray economies of scale in all of them, i.e. as we increase the quantity produced of each individual output, costs increase less than proportionally. We also find evidence of economies of scope for some (but not all) of the services provided within each category. This suggests that some services could be provided independently (or outsourced) within each hospital without affecting overall costs.

These results should be viewed as a contribution to the ongoing discussion of where and how should hospitals provide these services. In particular, they allow for an assessment of the possible cost savings which could arise from aggregating production in fewer hospitals. Moreover, the Portuguese National Health Service allows hospitals to outsource particular services (within the hospitals' premises) to public or private contractors. If economies of scale exist, such contractors could aggregate larger output levels and take advantage of them. However, and to the best of our knowledge, no Portuguese hospital has ever made use of this possibility.

Naturally, further research is needed. Whilst we have benefited from a particularly rich dataset, it is also true that we have used a relatively low number of observations because there are not too many hospitals in Portugal (less than 100) and because we have only used data for 2002-2006 (5 years). The estimation of flexible cost functions imposes great demands on the data because of the large number of explanatory variables used. Moreover, our analysis has not considered a separate strand of the literature which has emerged in the last few years: potential inefficiencies in hospital production. And it has also not considered recent changes in hospitals' payment mechanisms. These are likely to be the next steps in our research. 


\section{References}

[1] Aletras, V. (1999), "A comparison of hospital scale effects in short-run and long-run cost functions", Health Economics, 8, 521-530.

[2] Binkley, J. K. (1982), "The Effect of Variable Correlation on the Efficiency of Seemingly Unrelated Regression in a Two-Equation Model", Journal of the American Statistical Association, 77 (380), 890-895.

[3] Braeutigam, R. R. and Daughety, A. F. (1983), "On the estimation of returns to scale using variable cost functions", Economics Letters, 11(1-2), 25-31.

[4] Cameron, A. C and Trivedi, P. K. (2005), Microeconometrics: Methods and Applications, Cambridge University Press.

[5] Caves, D. W., Christensen, L. R., and Swanson, J. A. (1981), "Productivity growth, scale economies, and capacity utilization in the U.S. railroads, 1955-1974", American Economic Review, 71(5), 994-1002.

[6] Coase, R. (1937), "The Nature of the Firm", Economica, 4 (16), 386-405.

[7] Cowing, T. G. and Holtmann, A. G. (1983), "Multiproduct short-run hospital cost functions: Empirical evidence and policy implications from cross-section data", Southern Economic Journal, 49(3), 637-653.

[8] DGS (Direcção-Geral da Saúde) (2006), "Centros de Saúde e Hospitais: Recursos e Produção do SNS - 2005".

[9] DGS (Direcção-Geral da Saúde) (2007), "Centros de Saúde e Hospitais: Recursos e Produção do SNS - 2006".

[10] Fournier, G. and Mitchell, J. (1992), "Hospital costs and competition for services: a multiproduct analysis", Review of Economics and Statistics, 74(4), 627-634.

[11] Fraquelli, G., Piacenza, M. and Vannoni, D. (2004), "Scope and scale economies in multiutilities: evidence from gas, water and electricity combinations", Applied Economics, 36, pp. 2045-2057.

[12] Garcia, S. and Thomas, A. (2001), "The Structure of Municipal Water Supply Costs: Application to a Panel of French Local Communities", Journal of Productivity Analysis, 16, 5-29.

[13] Gonçalves, R. and Barros, P. P. (2009), "Economies of scale and scope in the provision of diagnostic techniques and therapeutic services in Portuguese hospitals", Economics Working Paper n. ${ }^{\circ}$ 4/2009, Faculdade de Economia e Gestão, Universidade Católica Portuguesa (Porto). 
[14] Grannemann, T. W., Brown, R. S. and Pauly, M. V. (1986), "Estimating hospital costs: A multiple-output analysis", Journal of Health Economics, 5(2), 107-127.

[15] Grossman, S. and Hart, O. (1986), "The costs and benefits of ownership: a theory of vertical and lateral integration", Journal of Political Economy, 94 (4), 691-719.

[16] Grossman, G. and Helpman, E. (2002), "Integration versus outsourcing in industry equilibrium", Quarterly Journal of Economics, 117 (1), 85-120.

[17] Gujarati, D. N. (1995), Basic Econometrics, 3rd Edition, McGraw-Hill.

[18] Herr, A. (2008), "Cost and technical efficiency of German hospitals: does ownership matter?", Health Economics, 17, 1057-1071.

[19] IGIF/ACSS (2004a), "Contabilidade analítica dos hospitais do SNS: 2002".

[20] IGIF/ACSS (2004b), "Serviço Nacional de Saúde: Contas Globais 2002".

[21] IGIF/ACSS (2004c), "Contabilidade analítica dos hospitais do SNS: 2003".

[22] IGIF/ACSS (2005), "Serviço Nacional de Saúde: Contas Globais 2003".

[23] IGIF/ACSS (2006a), "Contabilidade analítica dos hospitais do SNS: 2004", $2^{a}$ versão.

[24] IGIF/ACSS (2006b), "Serviço Nacional de Saúde: 2004".

[25] IGIF/ACSS (2006c), "Contabilidade analítica dos hospitais do SNS: 2005".

[26] IGIF/ACSS (2007a), "Serviço Nacional de Saúde: Relatório e Contas 2005".

[27] IGIF/ACSS (2007b), "Contabilidade analítica dos hospitais do SNS: 2006".

[28] IGIF/ACSS (2007c), "Elementos Económico-Financeiros e de Actividade Hospitais EPE 2005 / 2006"

[29] IGIF/ACSS (2008), "Serviço Nacional de Saúde: Relatório e Contas 2006".

[30] Li, T. and Rosenman, R. (2001), "Estimating hospitals costs with a generalized Leontief function", Health Economics, 10, 523-538.

[31] Maddala, G. S. (1992), Introduction to Econometrics, 2nd Edition, Prentice-Hall.

[32] Preyra, C. and Pink, G. (2006), "Scale and scope efficiencies through hospital consolidations", Journal of Health Economics, 25, 1049-1068.

[33] Rosko, M. (2001), "Cost efficiency of US hospitals: a stochastic frontier approach", Health Economics, 10, 539-551. 
[34] Rosko, M. and Chilingerian, J. (1999), "Estimating hospital inefficiency: does casemix matter?", Journal of Medical Systems, 23, 57-71.

[35] Smet, M. (2002), "Cost characteristics of hospitals", Social Science E Medicine, 55, 895-906.

[36] Staat, M. (2006), "Efficiency of hospitals in Germany: a DEA-bootstrap approach", Applied Economics, 38 (19), 2255-2263.

[37] Vita, M. G. (1990), "Exploring hospital production relationships with flexible functional forms", Journal of Health Economics, 9(1), 1-21.

[38] Vitaliano, D. (1987), "On the estimation of hospital cost functions", Journal of Health Economics, 6, 305-318.

[39] Williamson, O. (1975), Markets and hierarchies: analysis and antitrust implications, New York, NY: The Free Press.

[40] Williamson, O. (1979), "Transaction-Cost Economics: The Governance of Contractual Relations", Journal of Law and Economics, 22 (2), 233-261.

[41] Williamson, O. (1985), The Economic Institutions of Capitalism, New York: The Free Press.

[42] Young, S. (2005), "Outsourcing in the Australian health sector: the interplay of economics and politics", International Journal of Public Sector Management, 18 (1), 25-36.

[43] Zuckerman, S., Hadley, J. and Iezzoni, L. (1994), "Measuring hospital efficiency with frontier cost functions", Journal of Health Economics, 13, 255-280. 


\section{A Appendix}

\section{A.1 Data sources}

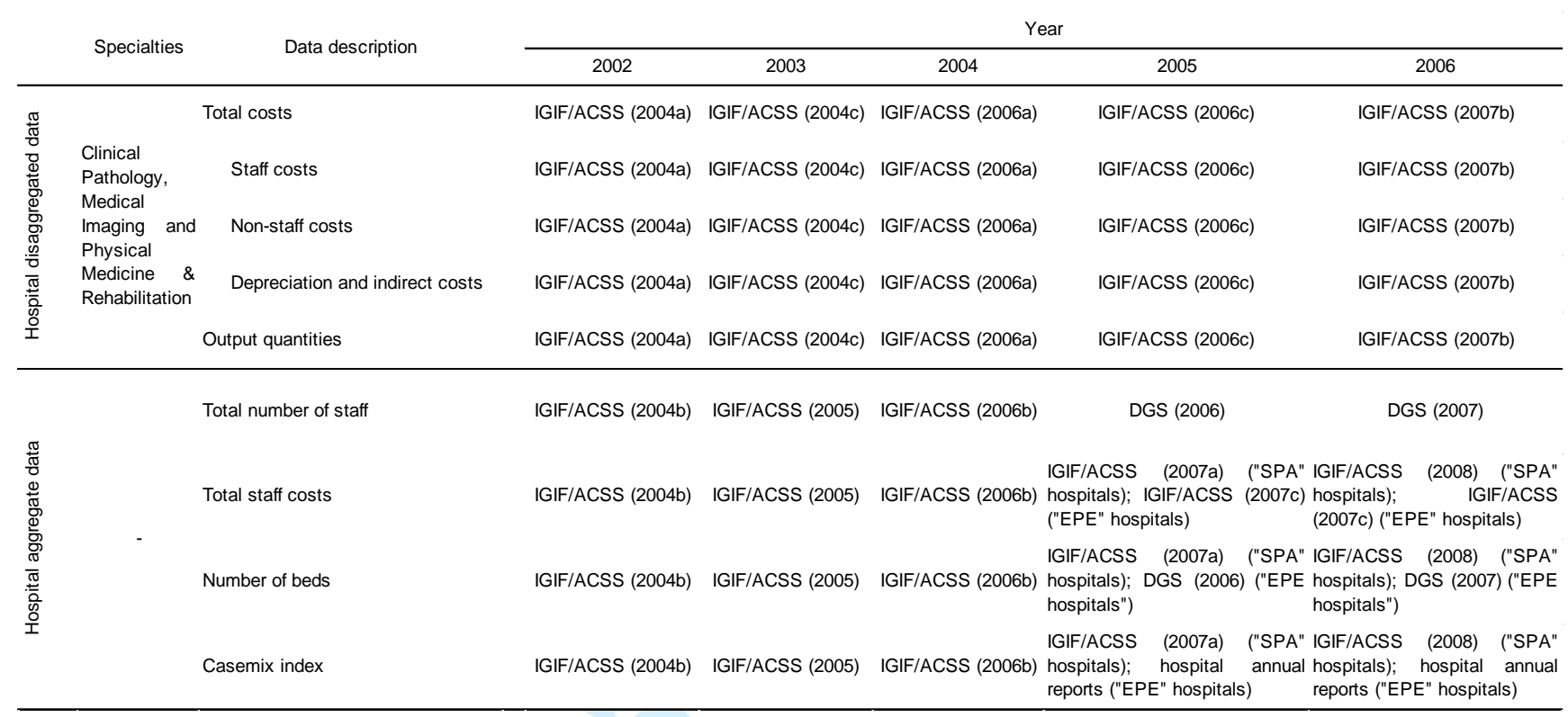

Table 9: Data sources

\section{A.2 Estimation results for a restricted model}

As we have outlined above, our estimation results (see Table 2) contain a relatively high number of insignificant variables, with multicollinearity being a possible (and likely) cause. Therefore, we have estimated a restricted version model for equations (4) and (6), taking a stepwise regression approach, in the hope of obtaining more statistically significant coefficients. However, in doing so, we may have committed a specification bias, by excluding relevant variables, and hence these estimates may be biased (see discussion in Section 4).

For each specialty, in order to arrive at the final restricted model to be estimated, we followed these steps:

1. Starting with the unrestricted model results (Table 2), we identify one output $\left(Y_{i}\right)$ whose $\beta_{i}$ coefficient is statistically insignificant and drop it (as well as all its interactions); if more than one $\beta_{i}$ is statistically insignificant, we drop the output whose interactions have more statistically insignificant coefficients;

2. We then reestimate the model and go back to step 1 if there is at least one statistically insignificant $\beta_{i}$ coefficient; otherwise, we proceed to step 3; 
3. We analyse the individual t-ratios of the remaining coefficients $\left(\beta_{i j}, \delta_{r i}\right.$ and $\left.\theta_{k i}\right)$ and drop the respective variables (one at a time) if they are statistically insignificant;

4. We then reintroduce the outputs (one at a time) eliminated in step $1-\beta_{i}$ coefficient only - to ensure that no statistically significant $\beta_{i}$ coefficients are eliminated, thus arriving at the final restricted model.

The estimation results are presented in Table 10. Notably, for each specialty, the outputs with a larger weight in total specialty costs were not dropped (because they have remained significant throughout) and their cost elasticities are the largest: ${ }^{34}$ output 1 (clinical chemistry) for Clinical Pathology, output 1 (radiology) for Medical Imaging and output 2 (physical therapy) for Physical Medicine and Rehabilitation. Table 11 presents the RTS estimates (see equation (7)) under this restricted model; we also report whether constant returns to scale are likely to exist $\left(H_{0}: R T S=\right.$ 1). ${ }^{35}$

\footnotetext{
${ }^{34}$ As in Table 2, except for Physical Medicine and Rehabilitation.

${ }^{35}$ The hypothesis of constant returns to scale is clearly rejected for Clinical Pathology and Medical Imaging. However, we must beware that the underlying estimates may be biased because of the specification bias.
} 


\begin{tabular}{|c|c|c|c|c|c|c|c|}
\hline & & \multicolumn{2}{|c|}{ Clinical Pathology } & \multicolumn{2}{|c|}{ Medical Imaging } & \multicolumn{2}{|c|}{$\begin{array}{l}\text { Physical Medicine and } \\
\text { Rehabilitation }\end{array}$} \\
\hline & & Model (1) & Model (2) & Model (1) & Model (2) & Model (1) & Model (2) \\
\hline Param. & Variable & Coef. & Coef. & Coef. & Coef. & Coef. & Coef. \\
\hline$\delta_{11}$ & $Y_{1} \cdot \ln \left(w_{1}\right)$ & & $0.010^{\star \star \star}$ & $-0.032^{* \star \star}$ & & & \\
\hline$\delta_{21}$ & $Y_{2} \cdot \ln \left(w_{1}\right)$ & & $0.005^{\star \star \star *}$ & & & $-0.006^{\star \star *}$ & \\
\hline$\delta_{31}$ & $Y_{3} \cdot \ln \left(w_{1}\right)$ & & $-0.006^{\star \star \star}$ & & & & \\
\hline$\delta_{41}$ & $Y_{4} \cdot \ln \left(w_{1}\right)$ & & & & & & \\
\hline$\delta_{51}$ & $Y_{5} \cdot \ln \left(w_{1}\right)$ & & & & & & \\
\hline$\delta_{61}$ & $Y_{6} \cdot \ln \left(\mathrm{w}_{1}\right)$ & & & & & & \\
\hline$\delta_{71}$ & $Y_{7} \cdot \ln \left(w_{1}\right)$ & & & & & & \\
\hline$\delta_{12}$ & $Y_{1} \cdot \ln \left(W_{2}\right)$ & & & $0.032 * * *$ & & & \\
\hline$\delta_{22}$ & $Y_{2} \cdot \ln \left(w_{2}\right)$ & & & & & $0.006 * \star \star *$ & \\
\hline$\delta_{32}$ & $Y_{3} \cdot \ln \left(w_{2}\right)$ & & & & & & \\
\hline$\delta_{42}$ & $Y_{4} \cdot \ln \left(w_{2}\right)$ & & & & & & \\
\hline$\delta_{52}$ & $Y_{5} \cdot \ln \left(\mathrm{w}_{2}\right)$ & & & & & & \\
\hline$\delta_{62}$ & $Y_{6} \cdot \ln \left(w_{2}\right)$ & & & & & & \\
\hline$\delta_{72}$ & $Y_{7} \cdot \ln \left(w_{2}\right)$ & & & & & & \\
\hline$\beta_{K}$ & $\ln (\mathrm{k})$ & $0.299 * \star *$ & $0.491^{* * \star}$ & $0.240^{* * *}$ & $0.428^{* * *}$ & $0.245^{* \star *}$ & $0.428^{* * *}$ \\
\hline $1 / 2 \beta_{K K}$ & $(\operatorname{lnk})^{2}$ & $0.184^{* \star *}$ & $0.250^{* * *}$ & $0.131^{* * *}$ & $0.158^{* \star *}$ & $0.061^{* *}$ & $0.078^{* *}$ \\
\hline$\sigma_{K 1}$ & $\ln (k) \cdot \ln \left(w_{1}\right)$ & $-0.054 * \star *$ & $-0.058^{\star \star \star}$ & 0.005 & $-0.066^{\star \star \star}$ & -0.008 & 0.009 \\
\hline$\sigma_{k 2}$ & $\ln (k) \cdot \ln \left(w_{2}\right)$ & $0.054 * \star \star *$ & & -0.005 & & 0.008 & \\
\hline$\theta_{K 1}$ & $\ln (k) \cdot Y_{1}$ & $-0.177^{* * *}$ & $-0.175^{\star * \star}$ & $-0.111^{* * *}$ & -0.051 ** & & \\
\hline$\theta_{K 2}$ & $\ln (k) \cdot Y_{2}$ & $0.011^{* *}$ & & & & -0.022 ** & $-0.048 * \star *$ \\
\hline$\theta_{K 3}$ & $\ln (k) . Y_{3}$ & & & $-0.015^{* * *}$ & $-0.027^{* * *}$ & & \\
\hline$\theta_{K 4}$ & $\ln (k) \cdot Y_{4}$ & & & $-0.018^{* * *}$ & & & \\
\hline$\theta_{K 5}$ & $\ln (k) \cdot Y_{5}$ & & & & & & \\
\hline$\theta_{K 6}$ & $\ln (k) . Y_{6}$ & & & & $-0.033^{\star \star \star *}$ & & \\
\hline$\theta_{K 7}$ & $\ln (k) \cdot Y_{7}$ & & & & & & \\
\hline & District hosp. & 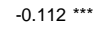 & $-0.296^{\star \star \star}$ & $-0.243^{\star * \star}$ & $-0.243^{\star \star \star}$ & 0.077 & 0.116 \\
\hline & Level 1 hosp. & -0.128 *** & $-0.359 * * *$ & -0.067 & 0.087 & -0.067 & 0.034 \\
\hline & D - Year 2003 & $-0.084 * * *$ & -0.086 & -0.035 & -0.023 & -0.059 & -0.016 \\
\hline & D - Year 2004 & $-0.089 * * \star$ & -0.051 & 0.023 & 0.028 & 0.021 & 0.059 \\
\hline & D - Year 2005 & -0.071 ** & -0.068 & 0.026 & 0.053 & 0.001 & 0.002 \\
\hline & D - Year 2006 & -0.067 ** & -0.036 & 0.037 & 0.089 & 0.005 & 0.081 \\
\hline D - & egion Algarve & 0.109 * & 0.206 * & 0.008 & -0.037 & -0.096 & -0.026 \\
\hline & Region Centro & -0.162 *** & $-0.284^{* \star *}$ & -0.119 ** & $-0.217^{\star \star \star *}$ & $-0.320^{* \star *}$ & $-0.477^{* \star \star}$ \\
\hline$D-R e$ & ion L. V. Tejo & 0.047 & 0.025 & 0.087 & 0.123 & 0.005 & 0.032 \\
\hline & Region Norte & $-0.121^{* \star *}$ & $-0.235^{* * *}$ & $-0.192 * * *$ & $-0.302 * * *$ & -0.203 ** & -0.284 ** \\
\hline & Casemix & -0.036 & -0.032 & $-0.275^{* * *}$ & $-0.175^{\star \star}$ & $0.483^{* * *}$ & $0.381^{* * *}$ \\
\hline$\alpha_{0}$ & Constant & $14.955^{* * *}$ & $15.035^{* * *}$ & $14.582^{* * *}$ & $14.696^{* * *}$ & $12.989^{* * *}$ & $12.905^{* * *}$ \\
\hline Number & of observations & 317 & 317 & 335 & 335 & 288 & 288 \\
\hline $\mathrm{R}^{2}(\cos$ & function) & 0.98 & 0.92 & 0.95 & 0.89 & 0.89 & 0.77 \\
\hline$R^{2}(\cos$ & share equation) & 0.21 & 0.18 & 0.49 & 0.15 & 0.62 & 0.01 \\
\hline
\end{tabular}

$\left.{ }^{(\star \star}\right)$ Significant at the $1 \%$ level; $\left({ }^{\star \star}\right)$ Significant at the $5 \%$ level; $\left({ }^{\star}\right)$ Significant at the $10 \%$ level

Table 10: Estimation results: restricted model

\begin{tabular}{|c|c|c|c|c|c|c|}
\hline \multirow[t]{2}{*}{ Ray economies of scale } & \multicolumn{3}{|c|}{ Model (1) } & \multicolumn{3}{|c|}{ Model (2) } \\
\hline & RTS & (std. error) & $\mathrm{H}_{0}: \mathrm{RTS}=1$ & RTS & (std. error) & $\mathrm{H}_{0}: \mathrm{RTS}=1$ \\
\hline Clinical Pathology & 1.09 & $(0.03)$ & ** & 1.33 & $(0.12)$ & 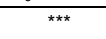 \\
\hline Medical Imaging & 1.22 & $(0.06)$ & 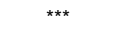 & 1.53 & $(0.3)$ & * \\
\hline Physical Medicine and Rehabilitation & 1.01 & $(0.13)$ & & 1.06 & $(0.13)$ & \\
\hline
\end{tabular}

Table 11: Ray economies of scale: restricted model 